\title{
Die extrapulmonale Tuberkulose
}

4. ärztlicher Fortbildungskurs der

Zürcher Kantonalen Liga gegen die Tuberkulose

in Arosa vom 6. bis 8. März 1952

Leitung: Dr. A. Wernli-Haessig

Verzeichnis der Vorträge
A. Wernli-Haessig (Zurich), Einführung
H. Wißler (Davos), Die Halsdrüsen-Tuberkulose
M. Amsler (Zurich), Augen-Tuberkulose
350
359

A. M. Fehr (Winterthur), Differentialdiagnose der KniegelenksafFektionen

H. Wehrlin (Davos-Clavadel), Zur Diagnose und konservativen Therapie der

Knochen- und Gelenkstuberkulose 387

W. Brunner (Zurich), Die Prinzipien der chirurgischen Behandlung der

Knochen- und Gelenktuberkulose 399

E. Held (Zurich), Die gynäkologische Tuberkulose 411

H. U. Gloor (Zurich), Urogenitaltuberkulose 419

W. Burckhardt (Zurich), Die Tuberkulose der Haut 434

E. Haefliger (Wald), Die Bedeutung der hämatogenen Streuung für die Ent-

wicklung der Lungentuberkulose 446

E. Uehlínger (St.Gallen), Pathologische Anatomie und Pathogenese der

hämatogenen Tuberkulose 455

W. Löffler und G. Jaccard (Zurich), Zur Klinik der hämatogenen tuber-

kulösen Streuphasen 482

Tuberkulose, Vol. IX, Fasc. 5 (1952) 26 